\title{
Comparison of the fans' behaviour and the induced grandstand vibrations on two different football stadia
}

\author{
Tomáš Plachý ${ }^{1, *}$, Michal Polák ${ }^{1}$ and Martin Verner $^{1}$ \\ ${ }^{1}$ Czech Technical University in Prague, Faculty of Civil Engineering, Department of Mechanics, \\ Thákurova 7, 16629 Praha 6, Czech Republic
}

\begin{abstract}
The paper presents comparison of the fans' behaviour on two football stadia in Prague, stadium of AC Sparta Praha and stadium of SK Slavia Praha. The behaviour of fans was monitored by camera and classified to different categories. The response (acceleration) of the grandstands was measured on both stadia at the most exposed positions. The comparison of the response of two grandstands with different bearing systems (a steel cantilevered structure and a reinforced concrete frame structure) induced by fans is presented and discussed in the conclusion.
\end{abstract}

\section{Introduction}

It is well known that the synchronized movement of a large group of spectators at the sport stadium can cause significant dynamic load on grandstands and subsequently cause their vibration. In some extreme cases, the induced vibrations are for the spectators uncomfortable and even visually observable. Excessive vibration can initiate panic of crowd and stampede. This can lead to injury and even death of some people in the crowd [1] and even cause the collapse of the grandstands [1]. It is difficult to predict the dynamic load caused by a moving group of people because its size and frequency composition depending on the type of physical activity of people are changing significantly.

A series of experiments focused on fans' behaviour and induced grandstand vibrations during football matches were carried out at the home stadium of the SK Slavia Praha football club from the Czech Republic which followed similar experiments performed on a steel cantilever grandstand structure at the AC Sparta football stadium in Prague $[2,3,4]$

The paper presents the main results of experimental analyses carried out during two matches SK Slavia Praha versus FK Teplice and AC Sparta Praha versus FK Teplice. The analyses were focused on the behaviour of spectators and on monitoring of the induced vibrations in the chosen grandstand sectors of the football stadia, where the most active fans were concentrated during a football matches. The used types of cheering and changes in fans' behaviour in various situations during the matches were investigated.

\footnotetext{
*Corresponding author: plachy@,fsv.cvut.cz
} 


\section{Description of the stadia}

The paper presents comparison of the fans' behaviour on two football stadia in Prague, in the Czech Republic, stadium of AC Sparta Praha and stadium of SK Slavia Praha. The load bearing structures of the grandstands in both observed stadium sectors are different. The grandstand on stadium of AC Sparta is built as a steel cantilevered structure (see Fig. 1 left) and the one on SK Slavia Praha stadium is constructed as a reinforced concrete frame structure (see Fig. 2 - left).

\subsection{Stadium of AC Sparta Praha}

The football stadium of the club AC Sparta Praha has been used for a long time since 1917. In the year 1934 it was decided to rebuild it for a capacity of 45000 spectators, but in the same year the main grandstand was burned down. So in the year 1937, new reinforced concrete one was opened. Between years 1967 and 1969 all other grandstands were replaced by new ones made from iron and concrete with the steel cantilever main beams. The stadium was completely modernized in 1994, only seated places remain and the stadium meets all international standards. The stadium has a heated lawn football pitch since the year 2002 .
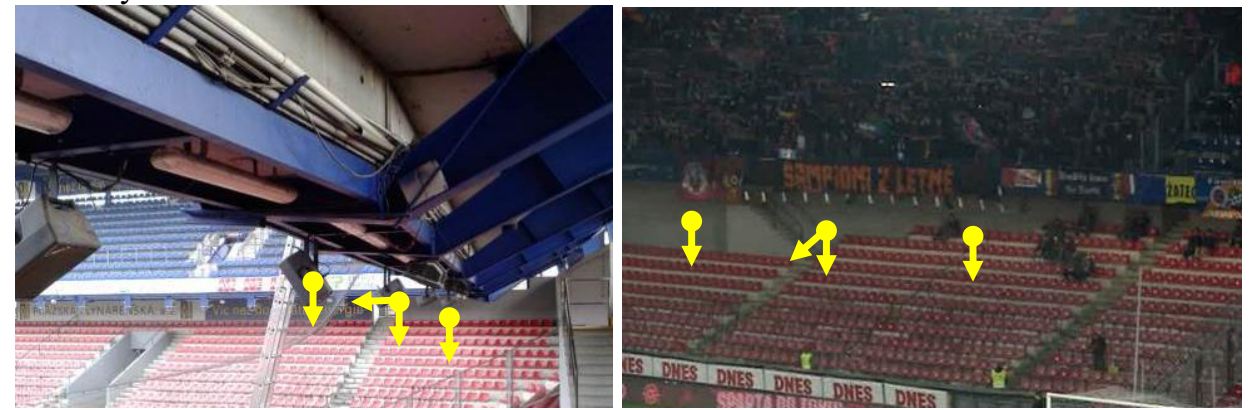

Fig. 1. The investigated grandstand at AC Sparta Praha stadium with positions of the accelerometers.

The dynamic response of the grandstand was observed at the ends of grandstand main beams where the maximal levels of induced vibrations were expected (Fig. 1). The part of the grandstand selected for an experiment was chosen based on the position where the most active fans usually gathered. The piezoelectric transducers Brüel\&Kjær of type 4507 B005 were attached to the lower beam flanges by using magnets. The measurement station Frontend 3050-B-040 Brüel\&Kjær and software Pulse were used for data acquisition. The obtained vibration records were modified by use of the Butterworth low-pass filter with cut off frequency $20 \mathrm{~Hz}$.

\subsection{Stadium of SK Slavia Praha}

The home stadium of SK Slavia Prague football club is called Eden Arena. It was put into operation in May 2008 and it is the most modern and with capacity of 20617 spectators also the largest football stadium in the Czech Republic. All places to sit are covered by a roof so they provide comfortable conditions for spectators during bad weather. On the other hand, the cantilever steel roof is constructed that the views from the grandstands are not restricted by any column (see Fig. 2 - right).

The investigated part of the grandstand is the reinforced concrete structure assembled from prefabricated elements. The basic structural members of the grandstand in the observed area are noticeable in Fig. 2 (left). The L-shaped reinforced concrete horizontal 
beams that create the walking and sitting area of the grandstand are simply supported on the inclined main beams and these ones are simply supported too but on the vertical columns. The joints between the inclined main girders and columns are recognizable in Fig. 2 (left).
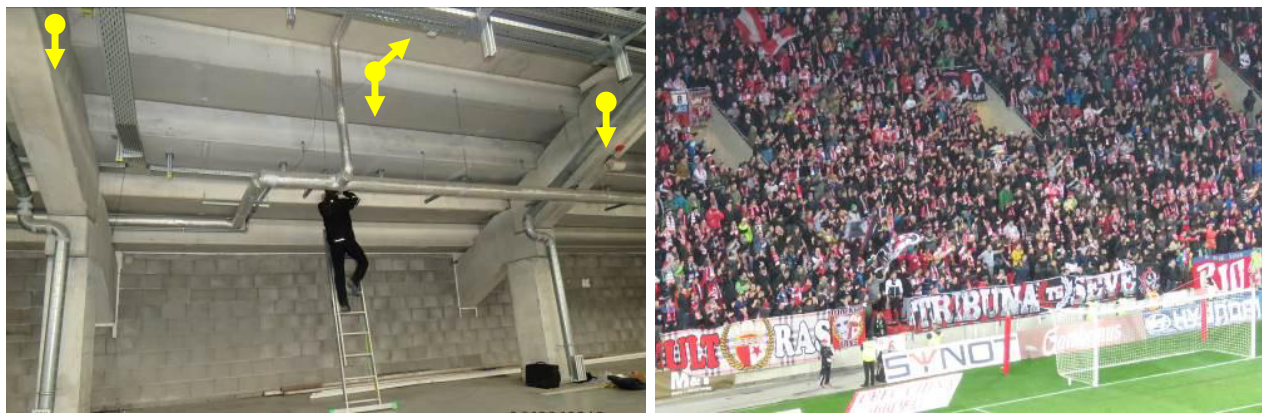

Fig. 2. The investigated grandstand at SK Slavia Praha stadium with positions of the accelerometers.

The dynamic response of the grandstand was observed in the middle of the L-shaped reinforced concrete horizontal beam (Fig. 2 - left) and on the inclined main beams under the support of the L-shaped beam (Fig. 2 - left). The position was chosen based on assumption where the highest concentration of the most active fans usually is. The same devices and measurement system were used as in the above mentioned case of AC Sparta Praha stadium.

\section{Results of the experimental analyses}

The first experiment was carried out at the home stadium of the AC Sparta Praha football club in Prague during the football match AC Sparta Praha vs. FK Teplice on March $21^{\text {st }}$ 2015 that Sparta won 1:0. The only goal was scored in the $89^{\text {th }}$ minute from the penalty.

The second experiment was realized at the home stadium of the SK Slavia Praha football club in Prague during the match SK Slavia Praha vs. FK Teplice on April $23^{\text {rd }}$ 2016. The match ended in a draw 2:2.

Behaviour of the most active fans in the monitored grandstand area was recorded by camera and the time length of each cheering type was evaluated for both matches from these records. The results can be compared in the Table 1 and in the Table 2. The designations of the basic behaviour types were assumed from the reference [1]. However, other additional types were detected and distinguished in the course of the matches. The brief description is mentioned below. Eleven main types of fans behaviour were categorized during both matches that affected the grandstand vibrations:

- static state - all fans passively watch the match and sit or stand statically,

- walking - this type of fans behaviour occurs during breaks when spectators are coming to their seats or when they are leaving their places,

- jumping of the $1^{\text {st }}$ type - independently - the fans are jumping en masse asynchronously and independently,

- jumping of the $2^{\text {nd }}$ type - rows vertically - the fans are joined together in separated lines and jump synchronously on the spot,

- jumping of the $3^{\text {rd }}$ type - rows horizontally - the fans are joined together in separated lines and move horizontally by synchronous jumping from right to left and back again usually in opposite directions in adjacent lines,

- jumping of the $4^{\text {th }}$ type - sit and jump - group of spectators sit down at first after that they concurrently jump up on a signal of their leader and begin continuous jumping promptly, 
- bouncing - the fans movement similar to jumping but the feet of persons remain in contact with the grandstand surface,

- swaying - the fans sway forward to support their shouted slogan and the entire motion is intensified moreover by arm movement,

- hand-clapping,

- goal scoring,

- Mexican wave - the sitting spectators stand up and raise their arms in turn creating the appearance of a wave passing through the stadium.

Table 1. Types of fans behaviour during the match AC Sparta Praha vs. FK Teplice.

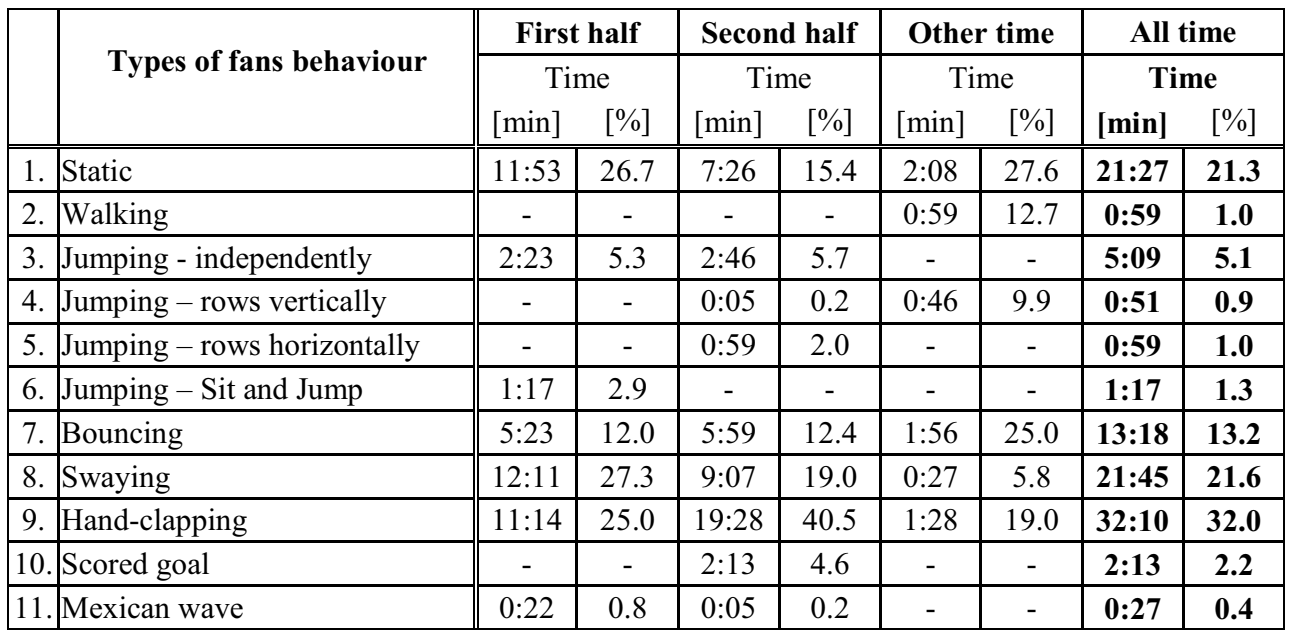

Table 2. Types of fans behaviour during the match SK Slavia Praha vs. FK Teplice.

\begin{tabular}{|c|c|c|c|c|c|c|c|c|c|}
\hline & \multirow{3}{*}{ Types of fans behaviour } & \multicolumn{2}{|c|}{ First half } & \multicolumn{2}{|c|}{ Second half } & \multicolumn{2}{|c|}{ Other time } & \multicolumn{2}{|c|}{ All time } \\
\hline & & \multicolumn{2}{|c|}{ Time } & \multicolumn{2}{|c|}{ Time } & \multicolumn{2}{|c|}{ Time } & \multicolumn{2}{|c|}{ Time } \\
\hline & & [min] & {$[\%]$} & [min] & {$[\%]$} & {$[\mathrm{min}]$} & {$[\%]$} & [min] & {$[\%]$} \\
\hline 1. & Static & $13: 32$ & 29.74 & $19: 50$ & 39.79 & $7: 03$ & 26.87 & $40: 25$ & 33.24 \\
\hline 2. & Walking & - & - & $0: 370$ & 1.24 & $16: 00$ & 60.99 & $16: 37$ & 13.67 \\
\hline 3. & Jumping - independently & $2: 25$ & 5.31 & $3: 54$ & 7.82 & - & - & $6: 19$ & $5: 20$ \\
\hline 4. & Jumping - rows vertically & - & - & - & - & - & - & - & - \\
\hline 5. & Jumping - rows horizontally & - & - & $0: 29$ & 0.97 & - & - & 0:29 & 0.40 \\
\hline 6. & Jumping - Sit and Jump & $0: 27$ & 0.99 & - & - & $0: 31$ & 1.97 & $0: 58$ & 0.80 \\
\hline 7. & Bouncing & $7: 00$ & 15.38 & $4: 47$ & 9.60 & $0: 10$ & 0.64 & 11:57 & 9.83 \\
\hline 8. & Swaying & $7: 32$ & 16.56 & $10: 13$ & 20.49 & $0: 16$ & 1.02 & 18:01 & 14.82 \\
\hline 9. & Hand-clapping & $13: 28$ & 29.60 & $6: 50$ & 13.71 & $2: 14$ & 8.51 & $22: 32$ & 18.53 \\
\hline 10 & Scored goal & $1: 06$ & 2.42 & $1: 45$ & 3.51 & - & - & $2: 51$ & 2.34 \\
\hline 11 & Mexican wave & - & - & $1: 26$ & 2.88 & - & - & $1: 26$ & 1.18 \\
\hline
\end{tabular}

The interesting examples of the response of the grandstands caused by type of fans behaviour No. 5 and the relevant frequency spectra are shown in Fig. 3 (AC Sparta stadium) and Fig. 4 (SK Slavia stadium). 

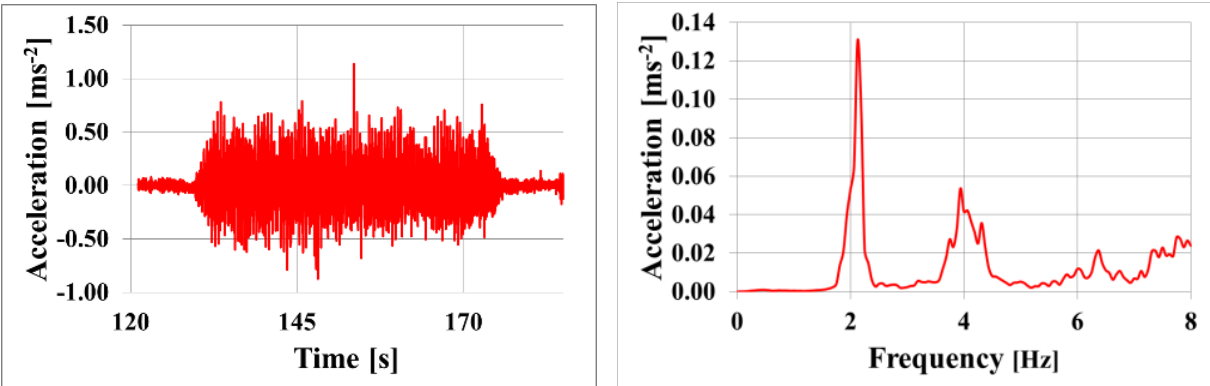

Fig. 3. The detail of the AC Sparta grandstand acceleration time record in vertical direction (left) and the relevant frequency spectrum that was measured on the middle girder during fans behaviour No. 5 .
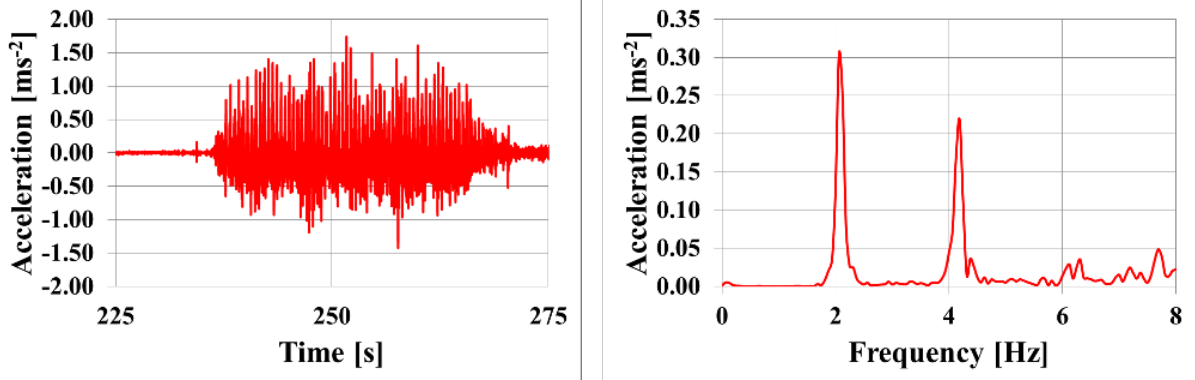

Fig. 4. The detail of the SK Slavia grandstand acceleration time record in vertical direction (left) and the relevant frequency spectrum that was measured in the middle of the horizontal beam during fans behaviour type No. 5 .
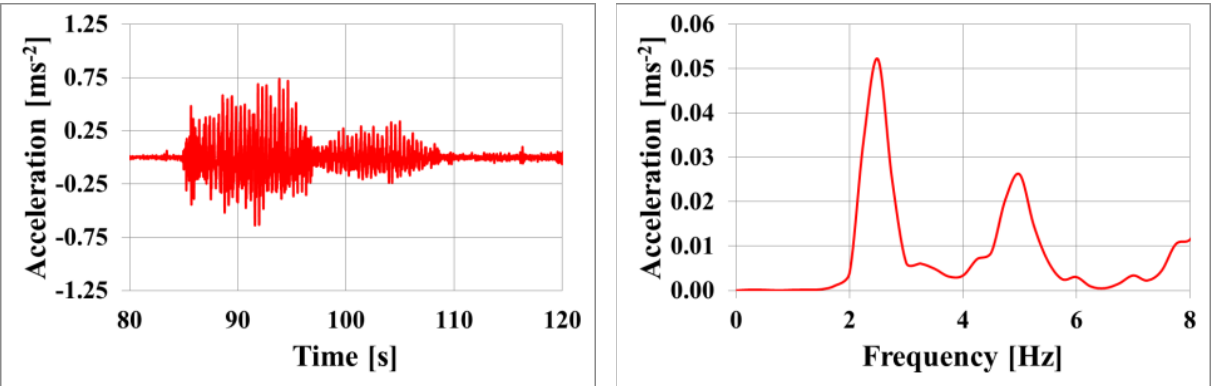

Fig. 5. The detail of the AC Sparta grandstand acceleration time record in vertical direction (left) and the relevant frequency spectrum that was measured on the middle girder during fans behaviour No. 10
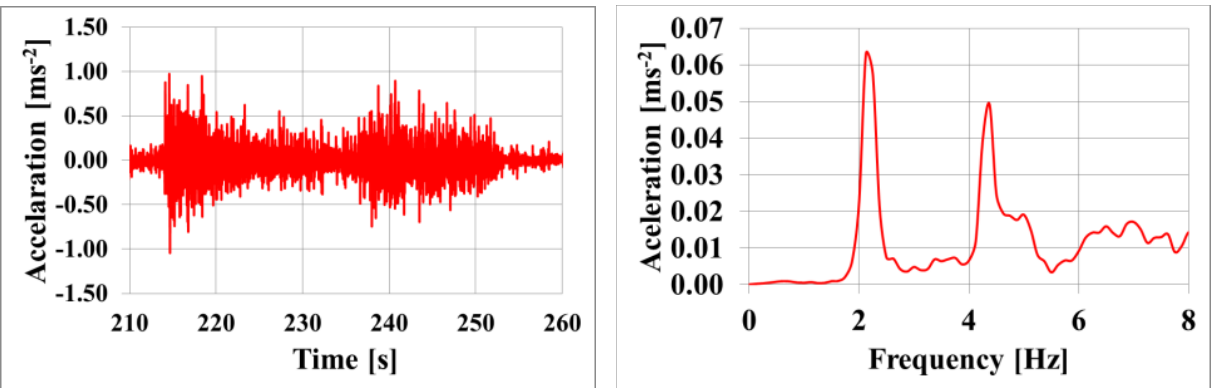

Fig. 6. The detail of the SK Slavia grandstand acceleration time record in vertical direction (left) and the relevant frequency spectrum that was measured in the middle of the horizontal beam during fans behaviour type No. 10 . 


\section{Conclusions}

The results of the fans behaviour monitoring are summarized in the Table 1 and in the Table 2. These tables show how the fans behaviour was changing during the observed matches and how their activity depends on quality of the match.

The most commonly used types of cheering in both matches were hand-clapping (type No. 9) or the static state (type No. 1) without cheering. The important parameter of the dynamic load caused by fans is not only time but also the percentage of active fans. This is why the largest vibration was caused during both matches when spectators support their team using Jumping of the $2^{\text {nd }}, 3^{\text {rd }}$ and $4^{\text {th }}$ type because $100 \%$ of them were involved in these activities. The organization of cheering by the leader in the stadium sector where the most active fans are gathered caused almost always the involvement of all of the spectators present at the sector.

The highest levels of the grandstands vibrations were evaluated during the cheering type Jumping of the $3^{\text {rd }}$ type (Table 1 - No. 5). The examples of evaluated accelerations for this type of cheering are shown in Fig. 3 and Fig. 4. The highest peak value of vertical acceleration $1.14 \mathrm{~ms}^{-2}$ was measured at the AC Sparta stadium and $1.54 \mathrm{~ms}^{-2}$ was measured at the SK Slavia stadium. The RMS values for these vibrations were $0.21 \mathrm{~ms}^{-2}$ at the AC Sparta stadium and $0.41 \mathrm{~ms}^{-2}$ at the SK Slavia stadium. For other types of cheering the vibration of these two stadia are lower, see Fig. 5 and Fig. 6 . The frequency spectra show that the excitation frequencies caused by fans do not depend on the types of fans, on both stadia the spectra look similarly (Fig. 3 to Fig. 6 - right). Nor the panic criteria nor the comfort criteria for the passive part of spectators on stadiums according the ISO 10137 were achieved.

This work has been supported by the Czech Science Foundation project No. GA15-15728S.

\section{References}

1. C. A. Jones, P. Reynolds, A. Pavic, Vibration serviceability of stadia structures subjected to dynamic crowd loads: A literature review, J. Sound Vib. 330, 1531 (2011)

2. M. Verner, M. Polak, T. Plachy, An Experimental Analysis of Grandstand Vibrations Caused by Crowd of Spectators during Two Football Matches, Appl. Mech. Mater 827, 312 (2016)

3. M. Verner, T. Plachy, M. Polak, An Experiment Focused on Fans Behaviour and Induced Grandstand Vibrations during a Football Match, Appl. Mech. Mater 837, 75 (2016)

4. M. Verner, M. Polak, T. Plachy, A Comparison of Spectators Induced Grandstand Vibrations and Fans Behavior during Two Football Matches between the Same Teams, Proceedings of $54^{\text {th }}$ International Conference on EAN 2016, 6p. (2016)

5. P. Reynolds, A. Pavic, Vibration performance of a large cantilever grandstand during an international football match, J. Perform. Constr. Fac. 20, 202 (2006)

6. ISO 10137:2007, Bases for design of structures - Serviceability of buildings and walkways against vibrations. 